\title{
The 'bikini lip reduction': A detailed approach to hypertrophic lips
}

\author{
Nabil Fanous MD FRCSC, Valérie J Brousseau BScH MDCM, Adi Yoskovitch MD
}

\begin{abstract}
N Fanous, VJ Brousseau, A Yoskovitch. The 'bikini lip reduction': A detailed approach to hypertrophic lips. Can J Plast Surg 2007;15(4):205-210.

Excessively large lips represent an occasional but significant challenge in aesthetic surgery. Previously described techniques focus largely on the simple excision of a strip of tissue to reduce the lips, without specific attention to the resultant lip contour or to the volume relationship between the lips. The present paper describes a new technique for lip reduction, called the 'bikini lip reduction'. This technique not only reduces the volume of the lips, but also restores an attractive labial contour, as well as an ideal volume relationship between the upper and lower lips. Because it is based on aesthetic analysis, this technique consistently yields both smaller and more aesthetically appealing lips. Simply stated, the bikini lip reduction consists of excision of a 'bikini top' (two cups and a middle strap) from the upper lip and a 'bikini bottom' (a triangle) from the lower lip. The aesthetic results and the patient satisfaction achieved through the bikini lip reduction technique have been very satisfactory.
\end{abstract}

Key Words: Aesthetic lip reduction; Lip analysis; Lip hypertrophy; Lip reduction; Surgical technique

\section{La réduction des lèvres par «coupe bikini » : Une approche détaillée des lèvres hypertrophiées}

\begin{abstract}
Des lèvres extrêmement larges représentent un défi occasionnel mais important en chirurgie esthétique. Les techniques décrites auparavant s'attardaient largement sur la simple excision d'une bande tissulaire pour réduire les lèvres, sans attention précise au contour des lèvres en résultant ou à la relation entre le volume des deux lèvres. Le présent article décrit une nouvelle technique de réduction des lèvres par " coupe bikini " Cette technique réduit non seulement le volume des lèvres, mais elle rétablit également un contour labial attrayant, de même qu'une relation de volume idéale entre la lèvre supérieure et la lèvre inférieure. Puisqu'elle se fonde sur une analyse esthétique, cette technique produit constamment à la fois des lèvres plus petites et plus attrayantes d'un point de vue esthétique. En termes simples, la réduction des lèvres par coupe bikini consiste à exciser un « haut de bikini » (deux bonnets et une bande centrale) sur la lèvre supérieure, et un « bas de bikini » (un triangle) sur la lèvre inférieure. Les résultats esthétiques et la satisfaction du patient obtenus grâce à la technique de réduction des lèvres par coupe bikini sont très intéressants.
\end{abstract}

A lthough thin lips represent the great majority of lip problems addressed by plastic surgeons, overly large lips are still seen occasionally, mostly among black and Asian patients.

There are few publications that discuss techniques for lip reduction (1-8). Apart from our approach (8), all others aim to achieve smaller lips by volume reduction without consideration of the relative proportion of the upper and lower lips, and without aesthetic analysis of the labial complex.

Our modified technique, coined the 'bikini lip reduction', involves resection of a bikini top shape - two cups and a strap from the upper lip and resection of a bikini bottom shape - a triangle - from the lower lip. A brief synopsis of this surgical approach was accepted for publication in Plastic and Reconstructive Surgery (8). The present article is a detailed account of the preoperative planning and intraoperative surgical steps.

The specific preoperative measurements, bikini lip reduction design and appropriate reductions are outlined, and results are discussed.

\section{METHODS}

Aesthetic analysis of the lips

The aesthetic analysis described herein was previously published in detail (9-12). In the frontal view (Figure 1), the ideal upper and lower lips form an aesthetically pleasing complex with upper, middle and lower linear contours represented by the letters $\mathrm{M}, \mathrm{M}^{\prime}$ and $\mathrm{W}$, respectively. Together, the lips form a lozenge or a diamond-shaped unit extending between the oral commissures, identified as $\mathrm{C}$ and $\mathrm{C}^{\prime}$.

The upper lip vermilion border has a soft $\mathrm{M}$ shape with two peaks at $\mathrm{B}$ and $\mathrm{B}^{\prime}$ corresponding to the philtral ridges. These peaks typically rise $3 \mathrm{~mm}$ to $5 \mathrm{~mm}$ above the midline of the vermilion border (point A). From B to C and $\mathrm{B}^{\prime}$ to $\mathrm{C}^{\prime}$, the vermilion border follows a lazy $S$ shape. At the midline, the typical height of the upper lip is approximately $7 \mathrm{~mm}$ to $8 \mathrm{~mm}$. The inferior border of the upper lip forms another M shape identified as $\mathrm{M}^{\prime}$.

The lower lip has two paramedian central enlargements ( $F$ and $F^{\prime}$ ), allowing for a perfect fit into the $\mathrm{M}^{\prime}$ of the lower border of the upper lip during lip closure. The volume of the lower lip is approximately $50 \%$ greater than that of the upper lip, with a midline height of approximately $10 \mathrm{~mm}$ to $12 \mathrm{~mm}$. The vermilion border of the lower lip has a W shape with lower points $\mathrm{D}$ and $\mathrm{D}^{\prime}$ approximately $3 \mathrm{~mm}$ farther apart on each side to the corresponding points $\mathrm{B}$ and $\mathrm{B}^{\prime}$ on the upper lip. The distance between $B$ and $\mathrm{B}^{\prime}$ is approximately $11 \mathrm{~mm}$ to $13 \mathrm{~mm}$, while the distance between $\mathrm{D}$ and $\mathrm{D}^{\prime}$ is approximately $18 \mathrm{~mm}$ to $20 \mathrm{~mm}$. The central portion of the lower vermilion border (D to $\mathrm{D}^{\prime}$ ) may be straight or form a gentle arch at point $\mathrm{E}$.

Institute of Cosmetic Surgery, Westmount, Montréal; Department of Otolaryngology - Head and Neck Surgery, McGill University, Montréal, Québec

Correspondence: Dr Nabil Fanous and Dr Valérie Julie Brousseau, 1 Westmount Square, Suite 1380, Montreal, Quebec H3Z 2 P9.

Telephone 514-935-9906, fax 514-935-6482, e-mail cosmeticsurgery123@videotron.ca 


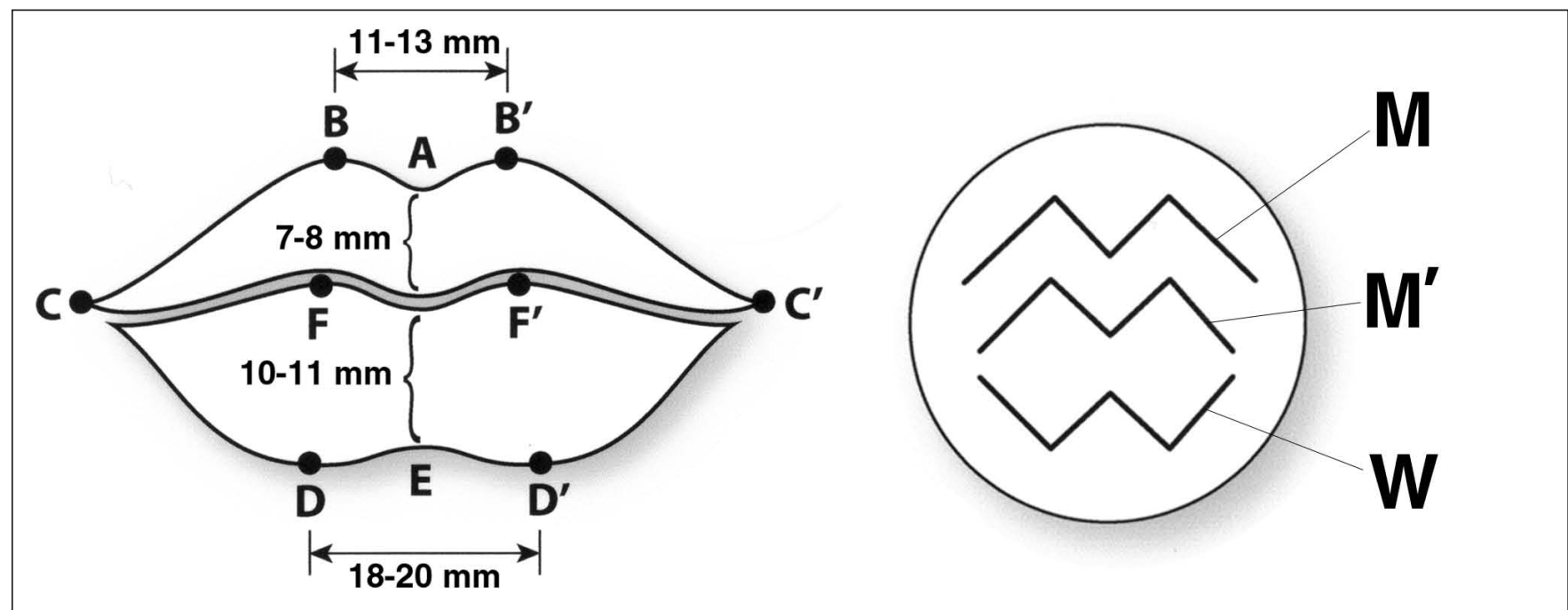

Figure 1) Aesthetic analysis of the ideal, youthful, attractive lips. The lip complex consists of three softly curving contours ( $M, M^{\prime}$ and $\left.W\right)$, with two upper peaks $\left(B\right.$ and $\left.B^{\prime}\right)$, two commissures $\left(C\right.$ and $\left.C^{\prime}\right)$ and two lower peaks ( $D$ and $\left.D^{\prime}\right)$. At the midline (A to E), the height of the upper lip is approximately $7 \mathrm{~mm}$ to $8 \mathrm{~mm}$, while that of the lower lip is $10 \mathrm{~mm}$ to $12 \mathrm{~mm}$. The volume of the lower lip is roughly $50 \%$ greater than that of the upper lip
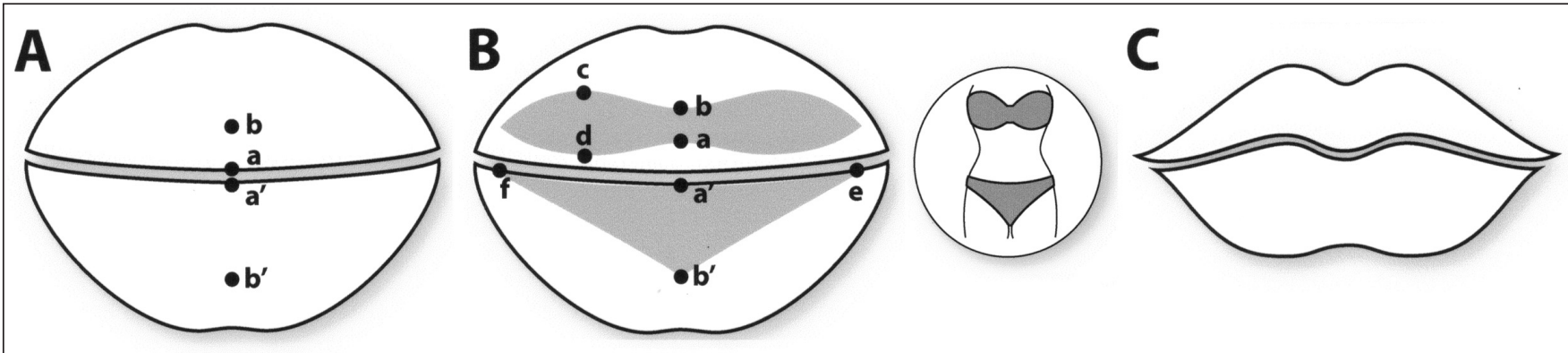

Figure 2) A Preoperative marking of the original ( $a$ and $\left.a^{\prime}\right)$ and new ( $b$ and $\left.b^{\prime}\right)$ dry/wet junctions; B The bikini incision, consisting of a 'bikini top' (two cups and middle strap) from the upper lip and a 'bikini bottom' (a triangle) from the lower lip; C Expected results, demonstrating the proper reduction and contouring of the lips while maintaining attractive aesthetic relative volumes and proportions

Both the upper and lower lips have a linear, thickened, cord-like delineation along the vermilion borders. A similar, more prominent elevation is present along the philtral edges of the upper lip. In profile view, both lips are slightly everted at the vermilion border, with the bulk of the lower lip being slightly posterior to that of the upper one.

\section{The concept of bikini lip reduction}

Traditionally, lip reduction techniques have focused on making both the upper and lower lip smaller without consideration to the relative volume balance between the lips (1-7).

Ideally, lip reduction should achieve three goals: decrease the overall volume of the labial unit, restore the soft curving outlines of the lips $\left(\mathrm{M}, \mathrm{M}^{\prime}\right.$ and $\left.\mathrm{W}\right)$ and maintain the ideal volume relationship between the lips, with the lower lip having a moderately larger volume than that of the upper lip.

The bikini lip reduction approach is based on these three goals. The bikini design, named after a woman's bathing suit (Figure 2), has two portions: the bikini top, composed of two lateral cups linked together by a central strap, and the bikini bottom, a triangle, with its apex located at the inferior aspect of the lower lip.

\section{Preoperative markings}

While the patient closes his or her lips in gentle repose, a fine marker is used to mark the midline of lips at their point of contact, namely, the actual midline of the dry/wet junction (Figure 2A, points a and $\mathrm{a}^{\prime}$ ). While the lips are slightly opened, the surgeon manipulates the lips with his fingers by pushing and rotating them inward, in an attempt to make them look smaller. The patient is then asked to close his or her lips to assess the planned lip reduction. This manoeuvre is repeated until the lips are aesthetically pleasing, making sure the volume of the showing lower lip is approximately $40 \%$ to $50 \%$ greater than that of the upper lip. While the lips are in this position, an additional reference point is made in the midline on the newly created dry/wet interface (Figure 2A, points $\mathrm{b}$ and $\left.b^{\prime}\right)$. The patient is then asked to open the lips to reveal a set of four central dots $\left(a, a^{\prime}, b, b^{\prime}\right)$.

The bikini design can now be established (Figure 2B). In the upper lip, the bikini top consists of two parallel lines approximately $1 \mathrm{~cm}$ long running horizontally through a and $\mathrm{b}$, forming the central strap. The strap then diverges to form two oval cups. The anteroposterior dimension (c to d) of the cups should be approximately double that of a to $b$. The ends of the cups should 

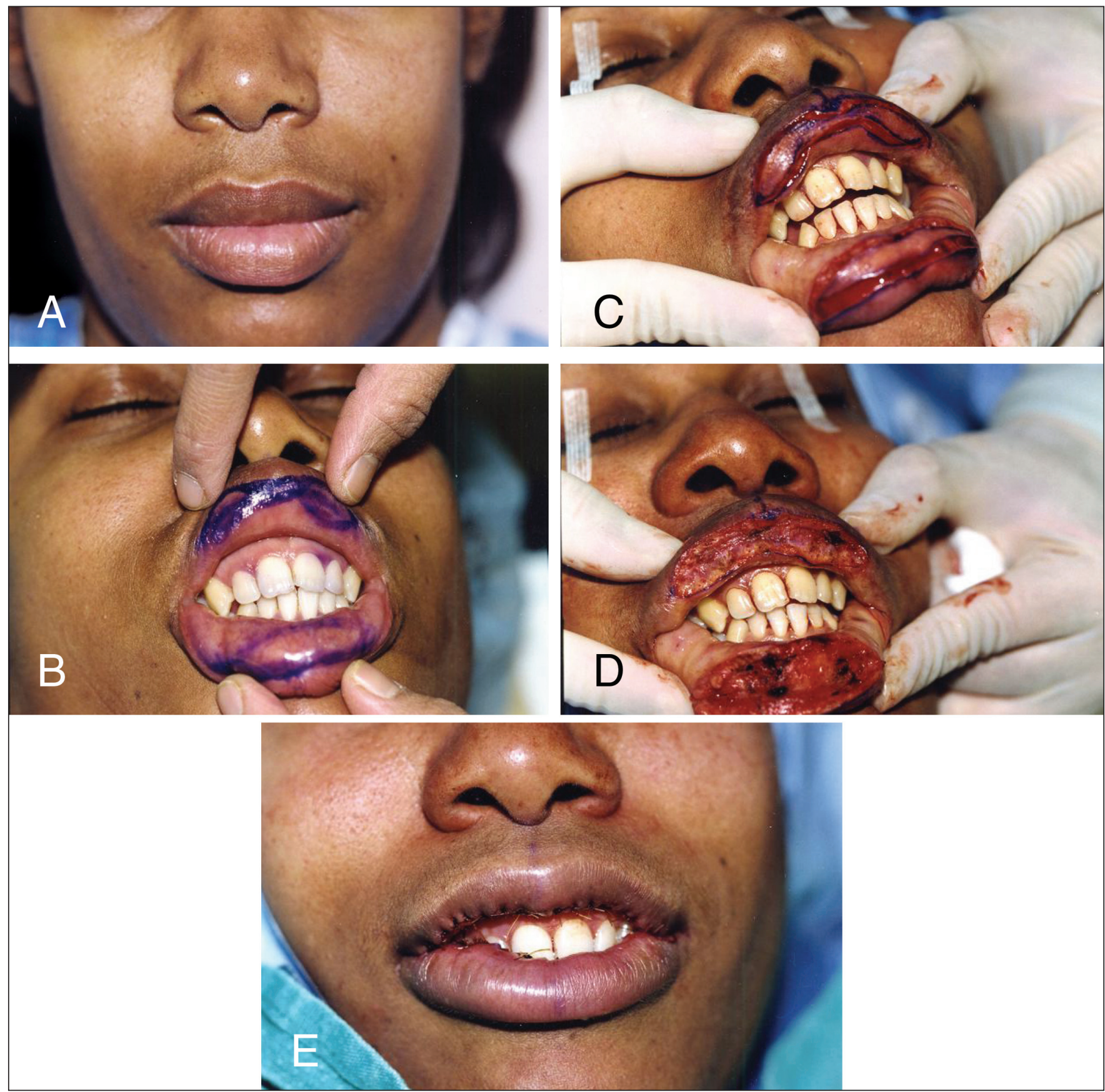

Figure 3) Surgical technique. A Preoperative lips; B Upper and lower lip markings; C Incisions of the 'bikini lip reduction' pattern; D Post bikini lip resection; E Immediately after closure

gently taper a few millimeters from the commissures. In the lower lip, the bikini bottom consists of a triangle $\left(e-b^{\prime}-f\right)$, where points e and $\mathrm{f}$ stop a few millimeters from the commissures.

The above guidelines may be modified as necessary to tailor the reduction parameters to the individual patient.

\section{The procedure}

Following the preoperative measurements and markings outlined above, local anesthesia is performed. Infiltration of the operative field is performed using around $5 \mathrm{~mL}$ to $8 \mathrm{~mL}$ of xylocaine $1 \%$ with adrenaline $1: 100,000$.

While squeezing the upper lip between the fingers of the left hand to limit bleeding, a number 15 blade is used to excise the bikini top (two lateral cups with a central strap) (Figure 2B) making sure the incision is slightly beveled so as to excise a triangular wedge of tissue. Hemostasis is achieved with the help of fine needle tip electrocautery. Excision of the bikini bottom is conducted in a similar way, followed by careful hemostasis. Both the upper and lower lips are then closed with a deep layer of interrupted 4-0 chromic sutures, followed by a cutaneous layer of interrupted 4-0 chromic sutures. No dressing is required. Figure 2C demonstrates the expected result of the operated upper and lower lips in terms of reduction, contouring and relative volume. Figure 3 demonstrates the sequence of surgical steps. 

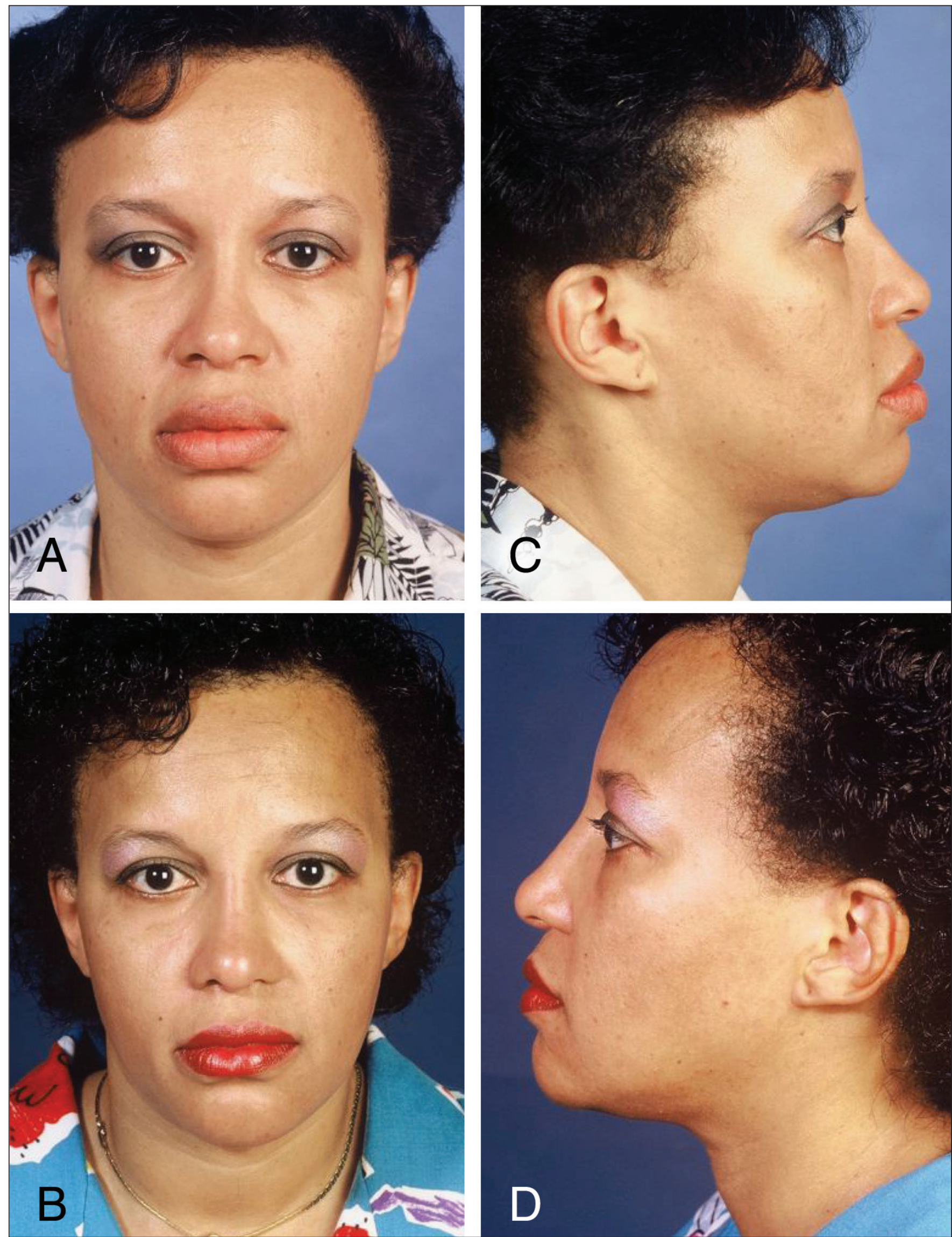

Figure 4) Example of bikini lip reduction. A Frontal view, preoperatively; B Frontal view, 15 months postoperatively; C Lateral view, preoperatively; D Lateral view, postoperatively 


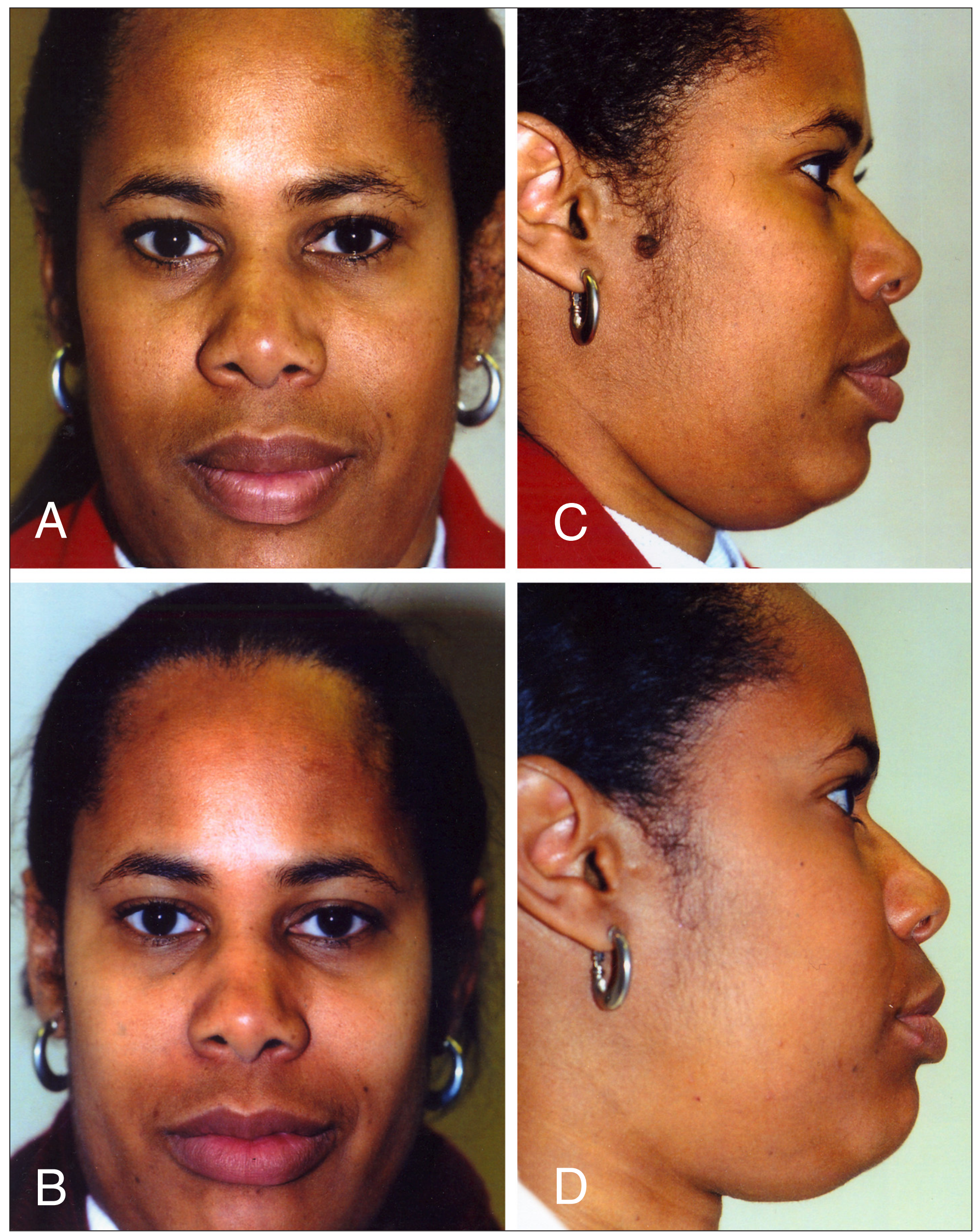

Figure 5) Example of bikini lip reduction. A Frontal view, preoperatively. This is the same patient as the one depicted during her surgery in Figure 3 B Frontal view, five months postoperatively. This is not yet the final result. It is important to realize that these lips will continue to shrink for almost two years following surgery, and will eventually look very close to the immediate postoperative appearance (Figure 3E); C Lateral view, preoperatively; $\mathrm{D}$ Lateral view, postoperatively 


\section{RESULTS}

The bikini lip reduction technique was performed on 11 patients. Age ranged from 22 to 48 years with a mean age of 28 years. Nine patients were female and two were male.

Postoperatively, all patients noted up to two weeks of marked labial swelling. The final result could take up to two years. This should be emphasized during the preoperative discussion. The swelling was easily managed with cold compresses. Postoperative pain was minimal. All mucosal scars healed nicely within three to six months. There was no significant complication. Examples of the postoperative results are presented in Figures 4 and 5.

\section{DISCUSSION}

Racial traits and heredity are the main etiologies of oversized lips. Other rare causes include inflammatory diseases (5) and congenital malformations (7).

In addressing hypertrophic lips, the common approach described in the literature advocates excising a horizontal wedge of soft tissue from both upper and lower lips. We believe the bikini lip reduction is a more thoughtful approach because it addresses the problem of lip volume while taking into account both the relative proportion of the lips and the aesthetic harmony of the labial unit. As in any lip surgery, preservation of the commissures is crucial to prevent labial banding and proper hemostasis is essential to prevent hematoma formation.

\section{SUMMARY}

Hypertrophic or large lips are an uncommon problem, almost exclusively encountered in black and Asian patients. Previously published techniques of lip reduction focus solely on simple reduction of the labial volume.

The bikini lip reduction is an approach based on aesthetic analysis. It achieves decreased lip volume while restoring harmonious relative proportions between the lips, resulting in a smaller and more attractive labial complex without undue westernization.

ACKNOWLEDGEMENTS: The authors express their thanks to the following people: Ildico Horvath, medical artist at the Montreal General Hospital, for her assistance in preparing the artwork; Minerva Khalife, clinical assistant, for her photographic contributions; Barbara Armbruster, MA, for the editing; Amanda Fanous for the literature search; and Stephanie Luetticken, MBA, for organizing the manuscript submission.

\section{REFERENCES}

1. Stucker FJ Jr. Reduction cheiloplasty. An adjunctive procedure in the black rhinoplasty patient. Arch Otolaryngol Head Neck Surg 1988;114:779-80.

2. Pierce HE. Cheiloplasty for redundant lips. J Natl Med Assoc 1976;68:211-2.

3. Field LM. Macrocheiloplasty. Principles and techniques. J Dermatol Surg Oncol 1992;18:503-7.

4. Rey R, Carreau JP, Gola R, Berbis P. Melkersson-Rosenthal syndrome. Value of reduction cheiloplasty. Ann Dermatol Venereol 1996;123:325-7.

5. Hauben DJ. Reduction cheiloplasty for upper lip hemangioma. Plast Reconstr Surg 1988;82:694-7.

6. Rees TD, Horowita SL, Coburn RJ. Mentoplasty, prognathism and cheiloplasty. In: Rees TD, Wood-Smith D, eds. Cosmetic Facial Surgery. Philadelphia: WB Saunders, 1973:494-553.

7. Botti G, Botti C, Cella A. A simple surgical remedy for iatrogenic excessively thick lips. Plast Reconstr Surg 2002;110:1329-34. (Discussion in 2002;110:1335-6).

8. Fanous N, Brousseau VJ, Yoskovitch A. The bikini lip reduction: An approach to oversize lips. Plast Reconstr Surg. Accepted for publication August 2006.

9. Fanous N. Correction of thin lips: 'Lip lift'. Plast Reconstr Surg 1984;74:33-41.

10. Yoskovitch A, Fanous N. Correction of thin lips: A 17-year follow-up of the original technique. Plast Reconstr Surg 2003;112:670-5.

11. Fanous N. Aging lips. Esthetic analysis and correction. Facial Plast Surg 1987;4:179-83.

12. Fanous N. Lip rejuvenation by vermilion advancement with volume and surface renovation. Facial Plast Surg Clin North Am 1997;5:71-6. 